\title{
Investigating a Typology of Trust Orientations towards National and European Institutions: A Person-Centered Approach
}

\author{
Anna Ruelens - Research Institute for Work and Society, University of Leuven (Belgium) \\ Ides Nicaise - Research Institute for Work and Society, University of Leuven (Belgium)
}

\begin{abstract}
There is a growing recognition that trust attitudes towards national and European institutions are systematically related. Despite substantial research interest, the exact nature of this relationship remains unclear. We argue that a person-centered approach with its focus on identifying groups of individuals with similar attitudinal profiles provides a valuable complement to the currently standard variable-oriented approach in addressing this challenge. To illustrate, we examine the extent to which a prior typology of diffuse support for the European Union (EU) would emerge from a multilevel latent class analysis of the Eurobarometer data (2014). Our results provide support for the investigated typology by identifying four distinct trust profiles at the individual level that coalesce into separate latent clusters at the country level. Our findings underscore the value of a person-centered approach for the study of EU support.
\end{abstract}

Keywords Political trust, EU support, Eurobarometer, person-centered approach, multilevel latent class analysis 


\section{Introduction}

In recent years, the scholarship on public support for the European Union (EU) has become increasingly interested in the interplay between trust attitudes at the European and national arena (e.g. Armingeon and Ceka, 2014; Harteveld et al., 2013; Muñoz, 2017; Muñoz et al., 2011; Sánchez-Cuenca, 2000; Verhaegen et al., 2017). The general consensus in the literature is that trust in national political institutions and trust in the EU are "fundamentally related" (Armingeon and Ceka, 2014, p. 99). Where scholars continue to disagree is on the exact nature of this relationship. The current debate is currently mired in issues concerning the strength and sign of the association between institutional trust at the national and supranational (EU) level (Muñoz, 2017; Muñoz et al., 2011). While some studies report a positive relationship between trust in national and EU institutions (e.g. Armingeon and Ceka, 2014; Torcal et al., 2012), others find the opposite effect (e.g. Sánchez-Cuenca, 2000).

Rather than adding one more regression-based study to the already existing body of literature, the present article offers an alternative approach with respect to both conceptual and methodological aspects of analyzing the relationship between trust attitudes towards national and European institutions. To date, much of the research conducted on this topic has adopted a variable-centered approach. Relying mostly on the correlation and regression techniques, this substantial line of scholarship has significantly advanced our knowledge of the nature and the determinants of institutional trust and EU support among European citizens. At the same time, when studying citizens' attitudes, variable-oriented research has focused too much on attitudes as variables and not enough attention has been given to citizens who hold these attitudes. In large part, this lack of focus on the individual could be attributed to the assumptions inherent in the variable-centered approach, namely (1) its emphasis on the variable as a central conceptual unit and (2) its assumption of homogeneity of the population. As a consequence, variable-oriented research can say little about how multiple trust attitudes are combined within individuals and how individuals with similar attitudinal profiles are represented in the European population. 
Unlike studies that use the variable-centered approach, the current study advances a personcentered perspective. Such a perspective inherently adopts a multidimensional view of attitudinal phenomena by focusing on a set of attitudes held by individual respondents. Relying on a person-oriented methodology, this approach is effective in identifying groups in the population that share a similar response pattern on a series of indicators. Up to now, only few studies on EU support have adopted the personoriented approach, albeit not explicitly. The notable example is the study of Martinotti and Stefanizzi (1995), who developed a typology of orientations towards the EU that was further elaborated by Armingeon and Ceka (2014). In these two studies, the authors suggest a number of different types of citizens based on the combination of attitudes towards institutions at the national and European level. Yet, to date, the existence of this typology in the European population has not been empirically examined, nor has it been conceptually clarified. The purpose of the current study is to introduce and apply the person-centered approach to the study of trust orientations towards national and EU institutions. Using the Eurobarometer 81.4 (2014) survey data, we investigate the typology of trust attitudes suggested in the literature on EU support. Furthermore, we validate the existence of the identified groups in the survey population. Finally, we examine the cross-national patterns of these groups at the level of countries in order to gain insights into the distribution of the established types within the EU.

To our knowledge, this is the first study that applies multilevel latent class analysis (MLCA) to the study of institutional trust in an explicitly person-centered framework. In doing so, this article advances the literature on EU support by providing conceptual, empirical, and methodological insights into the interplay between trust in national and EU institutions at the individual and country levels.

\section{Prior research}

Easton's distinction between specific and diffuse support has been important in offering conceptual guidance on theorizing and operationalizing different facets of public support for political system (Easton, 1965, 1975). In his reassessment of the concept of political support, Easton (1975) defines diffuse support as "evaluations of what an object is or represents---to the general meaning it has for a person---not of what 
it does" (p. 444). Understood as such, diffuse support contrasts sharply with specific support which relates to the "satisfactions that members of a system feel they obtain from the perceived outputs and performances of the political authorities" (Easton 1975, p. 437). Building on this conceptual distinction, scholars of political support have come to recognize trust in political institutions ${ }^{1}$ as a primary manifestation of institutional legitimacy and, ergo, of diffuse support for political system (Hooghe and Zmerli, 2011).

While much research has been conducted to examine trust in national political institutions as an expression of diffuse support at the domestic level, it is only recently that scholarship on EU support has begun to engage actively with the literature on political trust (Harteveld et al., 2013). In this line of research, diffuse support represents a generalized attitude towards EU institutions that, in their turn, embody the fundamental values and characteristics of the EU political system (Harteveld et al., 2013; Torcal et al., 2012). Accordingly, trust in European political institutions (frequently operationalized using trust in the European Parliament) has been used extensively both as a reflection of and as a direct proxy for evaluating diffuse support for the EU (e.g. Ares et al., 2017; Armingeon and Ceka, 2014; Harteveld et al., 2013; Torcal et al., 2012).

In exploring the nature and the sources of institutional trust at the EU level, Harteveld et al. (2013) identify 'three logics' of EU trust. The logic of rationality implies a utilitarian approach to EU trust based on the performative aspect of EU institutions both in terms of outcomes and processes of such performance, understood more generally (Harteveld et al., 2013). By contrast, the logic of identity relies on individuals' emotional attachment to the EU and to their nation. Finally, according to the logic of extrapolation, due to the limited knowledge of the European politics, citizens often rely on 'cues' from the national arena to form their opinions about EU institutions (Anderson, 1998; Harteveld et al., 2013). In this perspective, EU trust is mainly seen as a derivative of citizens' trust in national political institutions.

\footnotetext{
${ }^{1}$ In this article, following the convention adopted in the literature (see, for example, Zmerli

and Van der Meer, 2017), the terms 'political trust', 'institutional trust', 'confidence in political institutions', 'trust in political institutions' are used interchangeably.
} 
Common to all three logics of EU trust is their intrinsic connection to the national political sphere, in general, and to trust in national political institutions, in particular. Although its relevance is most pronounced in the reasoning behind the logic of extrapolation, trust in national institutions plays an important role in the argumentation related to the other two logics. For example, while it may be tempting to assume, following to the logic of rationality, that citizens form their opinions about the EU based solely on merits of EU institutions and hence independent of national influences, it is increasingly argued that individuals tend to benchmark the performance of EU institutions against that of national institutions (e.g. Rohrschneider, 2002; Rohrschneider and Loveless, 2010; Sánchez-Cuenca, 2000; for an in depth discussion of benchmarking see De Vries, 2018). Similarly, with respect to the logic of identity, recent research has identified national political trust as an important correlate to the development of European identity (Verhaegen et al.,2017). In short, rather than considering trust in national institutions and trust in EU institutions as operating in their respective domains, scholarship on EU support has come to view them as increasingly interrelated (Ares et al., 2017; Muñoz, 2017, Muñoz et al., 2011). Furthermore, most EU public opinion scholars concur that the direction of the relationship is from the 'first-order' national institutions to the supranational (EU) institutions (Muñoz, 2017; cf. Kumlin, 2011; Harteveld et al., 2013; Armingeon and Guthmann, 2014; Mair, 2013).

At the same time, empirical studies of EU support that examined the relationship between institutional trust at the national and EU level have yielded inconsistent results. In his seminal examination of support for European integration, Sánchez-Cuenca (2000) observes that low level of institutional trust at the national level leads to more support for integration at the EU level. The rationale for this negative relationship is explained by 'Europe as a lifebuoy' proposition (Harteveld et al., 2013). According to this line of reasoning, inefficient and corrupt domestic institutions negatively affect public trust in national politics, thereby lowering the opportunity cost of transferring sovereignty to the supranational level (Sánchez-Cuenca, 2000). This conclusion is challenged by the results of the study by Armingeon and Ceka (2014). Using the Eurobarometer data (2007-2011), the authors find that trust in national political institutions is positively associated with trust in EU institutions. This positive relationship is explained with 
reference to cue theory (Anderson, 1998). Specifically, given the generally limited knowledge about the European politics, citizens tend to evaluate European institutions on the basis of institutional performance at the domestic level. According to this rationale, confidence in national institutions serves as a proxy for EU trust (cf. kritzinger2003influence). Yet, the results of the study by Harteveld et al. (2013) provide no support for the 'Europe as a lifebuoy’ proposition (Sánchez-Cuenca, 2000; Muñoz 2011institutional) or for the 'national political trust as a proxy' argument. On the other hand, more recent work on the spillover effects of diffuse support from the national to the EU level corroborates the view that trust in domestic representative institutions and EU trust are positively related (Ares et al., 2017; Torcal and Christmann, 2019).

In an insightful attempt to account for conflicting results, Muñoz et al. (2011) argue that the direction of the association between trust attitudes at the national and EU level may differ depending on the level of analysis, one has chosen to focus on. Using both single and multilevel regression analysis the authors find that, whereas, at the individual level, trust in national institutions and trust in the European Parliament are positively associated, and thus 'congruent', at the country level, this relationship is negative or 'compensatory' (Muñoz et al., 2011). The authors conclude that "institutional trust seems to be a common underlying attitude that operates regardless of the specific level of government" (Muñoz et al., 2011, p. 569). This conclusion is echoed by Harteveld en al. (2013), who contend that their findings imply that "a common source exists for trust in institutions on both levels, possibly an aspect of personality, general outlook on life or social standing" (Harteveld et al., 2013, p. 557).

Although perhaps unintentionally, this observation by Harteveld en al. (2013) challenges the standard investigation of the relationship between institutional trust at the national and EU level in two important respects. First, trust in national political institutions and trust in EU institutions are seen as different dimensions of the multidimensional construct, possibly that of political trust. ${ }^{2}$ Second, the

\footnotetext{
${ }^{2}$ Although the literature on political trust appears to support the view that individual attitudes towards political institutions constitute a single dimension (Hooghe, 2011; Mishler and Rose, 2007; but cf. Van der
} 
conceptual and empirical focus in the statement by Harteveld en al. (2013) is shifted to the individual. As pertains to the present study, these two considerations pave the way to our argument. Specifically, we argue that in order to advance the current debate further, it is necessary to complement prior research on national and EU political trust, which mainly relied on the variable-oriented approach, with studies using the personoriented approach.

In the remainder of this article, we first outline the main differences between the two approaches and describe the typologies of EU support by Martinotti and Stefanizzi (1995) and Armingeon and Ceka (2014), examined in this study. We then discuss the method and the data used in our analysis. After presenting the results of the single-level and multilevel latent class analysis, we review how these findings contribute to the existing literature on EU support. The article concludes with some caveats and specific suggestions for future research.

\section{From a variable-centered to a person-centered approach}

As reflected in its name, the variable-oriented perspective considers the variable, rather than the individual, to be a main conceptual and analytical unit (Bergman and Lundh, 2015). Given its predominant focus on the variable, this approach is well suited for abstracting specific attitudes or attributes from individuals and analyzing the association between the constructs of interest using correlation and/or regression methods. In the variable-oriented perspective, the dimensions of a specific construct are studied separately or as predictors of each other. In addition, a postulated relationship (usually linear) between the variables is considered to hold across the entire population under study. To illustrate, the research question at the heart

Meer and Ouattara, 2019; Fisher et al., 2010), the research on multidimensionality of political trust has been limited to the national political institutions, and offers no empirical evidence of unidimensionality of political trust in multilevel system. 
of the article by Muñoz et al. (2011) is highly representative of the types of questions being posed by the variable-oriented approach in the research on EU support. The question is stated as follows: "Does trust in national institutions foster or hinder trust in the institutions of the European Union (EU)?" (Muñoz et al., 2011, p. 551). In this example, the relationship between national political trust and EU trust is conceptualized at the level of variables and the purpose of the investigation is to relate the two in terms of predictor and outcome variables.

By shifting conceptual focus from the variable to the individual, the person-centered approach provides a valuable complement to the variable-oriented approach. Indeed, to paraphrase Bergman et al., (2003, p. 23), it is individuals, not variables, who trust. Instead of focusing on one or another attitudinal dimension, the person-oriented perspective investigates how multiple attitudes are combined within individual citizens. In this way "the person is conceptualized as an integrated totality rather than as a summation of variables" (Magnusson and Allen, 1983, p 372). In addition, unlike the variable-centered approach, which assumes that the sample population is homogeneous, the person-centered approach recognizes the heterogeneity in the population. Accordingly, rather than abstracting attitudes from individuals, studies using the person-oriented approach identify typical combinations of attitudes or 'profiles' among the respondents and group the respondents into types according to their response patterns. As a consequence, the person-centered approach offers a multidimensional and a more complete understanding of both the attitudes and the individuals who hold them. As aptly stated by Bonikowski (2017): "If we take survey responses to be indicative of beliefs, then patterns of responses that appear to 'hang together' within latent classes can be interpreted as indicative of distinct orientations” (p. 155).

Moreover, the person-centered perspective makes it possible to examine the differences among the identified types in their trust dispositions. In this view, rather than conceptualizing political trust at one level as a 'cause' of trust attitudes at another level, as is often suggested in the extant literature, institutional trust is seen as an interrelated system of trust attitudes. At the same time, it is important not to confuse the person-centered perspective with an approach that concentrates on individual-level explanations. For example, individual-level characteristics (such as sociodemographic factors) are often included in the 
variable-oriented studies, nevertheless, the focus of these studies remains exclusively on the relationships among variables, rather than among individuals in their differences and similarities.

\section{Theoretical antecedents}

Despite its potential to provide unique insights into the subject area, until now, only a small number of studies have used the person-centered approach to examine public attitudes related to political sphere. These few examples are found in the field of identity (Huang, 2005), nationalism (Bonikowski and DiMaggio, 2016; Bonikowski, 2017, political participation (Oser et al., 2013), and citizenship norms (Hooghe and Oser, 2015; Hooghe et al., 2016). A more recent and worth mentioning attempt at investigating political trust by "thinking about individuals and how they might trust in similar or different ways" is provided by Wu and Wilkes (2018). Based on the analysis of the World Values Survey (WWS) and the US General Social Survey (GSS), the authors identified patterns of trust and distrust in political institutions at the national level.

In the literature on EU support, the examples of studies using the person-centered approach are even more scarce. Notably, although not explicitly working within the person-oriented framework, Martinotti and Stefanizzi (1995) in their study of the relationship between national and European legitimacy proposed an a priori typology of national and supranational orientations. Relying on two measures from the Eurobarometer, namely 'satisfaction with national democracy' and 'evaluation of EC membership', the authors created a fourfold classification both at the individual and at the country-level. Their typology of orientations towards the national and EU systems at the individual level included four distinct types: (1) 'integrated', characterized by a positive orientation both towards the European Community (EC) and their own national political system; (2) 'nation statist', characterized by a sceptical orientation towards the EC and a positive attitude towards their domestic political system; (3) 'alienated', characterized by feeling of a alienation both towards the European and their own political system; and (4) 'innovators/escapists', characterized by sceptical attitudes towards the national political system and by positive expectations about 
the European integration (Martinotti and Stefanizzi, 1995). In an exploratory fashion, the authors applied this typology both to the individual and country level of analysis, to reveal the complexity of the relationship between national and supranational orientations.

At the country-level, Martinotti and Stefanizzi (1995) identified the following four groups of countries based on the typical profile of orientations of their citizens: the predominantly integrated (Luxembourg, Ireland, the Netherlands, and Portugal); the integrated plus innovator/escapist (France, Belgium, and Spain); the integrated plus nation statist (Denmark, Germany, and Britain); and the predominantly innovator/escapist (Italy and Greece). In addition, the authors grouped the countries on the basis of the social and political characteristics associated with the specific type of orientation, including occupational class, age, left-right ideology, frequency of political discussion and knowledge about the European Community.

Building on the conceptual and empirical insights of Martinotti and Stefanizzi (1995), Armingeon and Ceka (2014) have adapted the original typology of orientations to the study of EU support. Using the Eurobarometer survey indicators, the authors developed a two-by-two classification matrix of trust orientations towards national and EU institutions Table 1.

\section{INSERT TABLE 1 ABOUT HERE}

Table 1. Types of attitudes toward national governments and EU

\begin{tabular}{lcc}
\hline & Tend to trust the EU & Tend not to trust the EU \\
\hline $\begin{array}{l}\text { Tend to trust national } \\
\text { government }\end{array}$ & 'trusting' & 'nationalist' \\
$\begin{array}{l}\text { Tend not to trust national } \\
\text { government }\end{array}$ & 'escapist & 'detached' \\
\hline
\end{tabular}

Note: Reproduced from Armingeon and Ceka (2014) with authors' permission.

Departing slightly from the original terminology of Martinotti and Stefanizzi (1995), Armingeon and Ceka (2014) provided the following definitions of the suggested types: 
- The 'escapist'---someone who thinks that the national government is not trustworthy; so all hopes are put on the EU.

- The 'nationalist'---someone who thinks that the national government is particularly trustworthy while the EU, as a supranational body, does not merit any trust.

- The 'trusting' citizen---someone who trusts both their national government and the EU. Basically she thinks that governments are doing fine — both at the national and the supranational level.

- Finally, the 'detached' citizen---someone who is convinced that neither the national nor the supranational government merits any trust (Armingeon and Ceka, 2014: 89).

In their study, Armingeon and Ceka (2014) used this multidimensional framework of trust orientations to test their argument about the importance of domestic institutional context for EU evaluation. Specifically, the authors investigated the relative sizes of types of support for national and European government by cross-tabulating two trust indicators. They found that the 'detached' and the 'trusting' types together formed the largest group across EU countries, with the share of 'detached' citizens having increased following the economic crisis of 2008-2010. According to the study's findings, the 'nationalist' type constituted the smallest group in the Eurobarometer sample preceded by the 'escapist' type. While mostly comparing the four types at the aggregate level across twenty-seven European countries, Armingeon and Ceka made a distinction between countries that were under IMF conditionality and those that were not. This distinction allowed to examine whether the economic crisis and the austerity policies effected support for the EU. The results of their study confirmed that the countries under IMF conditionally were characterized by a more pronounced increasing trend in the proportion of the detached and alienated citizens.

The study of Armingeon and Ceka (2014) provides a good starting point for the person-oriented analysis since their framework offers a clear typology that can be tested empirically. To this date, however, this typology of trust attitudes has not been explored and/or validated in a cross-national sample of the 
European population. The aim of the present article is therefore to investigate the existence and the structure of the typology of trust attitudes towards national and European institutions using rigorous person-oriented methodology. Further, by means of the multilevel latent class analysis, we examine whether and how the identified types are manifested at the country level. By addressing these two research goals, the current study aims to gain new insights into the relationship between trust orientations at the national and EU level.

\section{Method and data}

\subsection{Multilevel latent class analysis}

The genuine person-centered perspective necessitates the use of a person-centered method. Although a number of different person-oriented analytical techniques exist, among them multidimensional scaling, cluster analysis, relational class analysis, and more recently, response pattern analysis, latent class analysis (LCA) is an ideal method for investigating the existence of distinct types of respondents based on a number of empirical categorical indicators. ${ }^{3}$ LCA is a multidimensional approach that allows to classify individuals into meaningful groups on the basis of correspondence of their attitudinal patterns. Similar to LCA, both relational class analysis and response pattern analysis focus on identifying patterns in survey responses. These two methods, however, are more concerned with analyzing the structure of the responses rather than the attitudes proper. ${ }^{4}$ Furthermore, LCA is both probabilistic, in that it describes how the probabilities of a set of observed categorical indicators vary across unobserved latent classes, and a model-based approach, in that it applies statistical models to contingency tables and provides fit criteria to assess model

\footnotetext{
${ }^{3}$ Latent profile analysis (LPA) is used to uncover latent types based on continuous observed indicators.

${ }^{4}$ Relational class analysis (RCA) aims to group the respondents whose attitudes follow similar relational patterns ((Baldassarri and Goldberg, 2014; Goldberg, 2011). Response pattern analysis looks for consistency in patterns of responses (Wu and Wilkes, 2018).
} 
performance. As a versatile and powerful approach, LCA makes it possible "to engage in cross-national comparison without resorting to country-level cultural reductionism or to its converse, variable-based individualism (Bonikowski, 2017, p. 169).

Although latent class analysis has been available for many years (Lazarsfeld and Henry, 1968; Goodman, 1974; McCutcheon, 1987; Hagenaars, 1993), its application to the study of political attitudes has been mostly limited to the study of nationalism and citizenship norms (see, for example, Bonikowski and DiMaggio, 2016; and Hooghe et al., 2016). Furthermore, previous applications of LCA in crossnational political research, have generally neglected to take into account the inherent multilevel structure of survey data with individual respondents nested within countries. The only two notable exceptions known to us are the study of Morselli and Passini (2012) on disobedience and support for democracy and the study of Morselli and Glaeser (2018) on economic conditions and social trust. Yet, ignoring the hierarchical nature of survey data violates the assumption of independence of observations, which is central to LCA. Moreover, using a single-level approach with multilevel data ignores contextual effects that may potentially play an important role in the explanation. Indeed, recent studies of diffuse support for the European Union have demonstrated the significance of economic and political context for explaining attitudes towards EU institutions (Ares et al., 2017; Torcal and Christmann, 2019). Hence, as with the use of multilevel regression within the variable-oriented paradigm, a multilevel approach is necessary.

Similar to the traditional single-level LCA, multilevel latent class analysis (MLCA) identifies subpopulations using the observed indicators while taking into account the nested character of the survey data. It is therefore an optimal technique to address our research objectives. ${ }^{5}$ In the current study, we adopt

\footnotetext{
${ }^{5}$ An alternative specification could be to conduct the individual-level LCA with a country as a covariate, however MLCA offers several advantages over this option. Because MLCA allows for the simultaneous analysis of individual and country segments, it is more efficient. In addition, its interpretation (especially in its nonparametric specification) is more intuitive than that of a single-level LCA with a country covariate, particularly when the number of higher-level units is large. Furthermore, compared to the alternative
} 
a nonparametric approach to MLCA (Vermunt, 2003, 2008; Asparouhov and Muthén, 2008, Henry and Muthén, 2010). In contrast to a parametric approach, which assumes a normal distribution of the random means, the nonparametric approach makes a less strong assumption by specifying a multinomial distribution. Relaxing a strong assumption of normality provides two main advantages. First, it makes the estimations less computationally intensive; and second, it allows for a less abstract and, hence, more interpretable classification solution at the group level, all without losing accuracy (Finch and French, 2014). A comprehensive description of MLCA and a nonparametric approach can be found in Vermunt (2003, 2008).

A schematic representation of a nonparametric MLCA model with individual respondents clustered in countries is shown in Figure 1. The model consists of a within-country (Level 1) and a between-country (Level 2) component. Six indicators (u1-u6) and four latent classes (CW) are defined at Level 1, with filled circles representing the random means for the within-country latent classes (three random means for four classes are specified). These random means define Level 2 latent classes (CB) and are indicated by C\#1, C\#2 and C\#3 at the between-country level.

specification, MLCA does not rely on country mean comparisons which are "problematic under the violation of strict (scalar) invariance of trust measures" (Morselli and Glaeser, 2018). Finally, MLCA specification allows for the inclusion of covariates at different levels of data. 


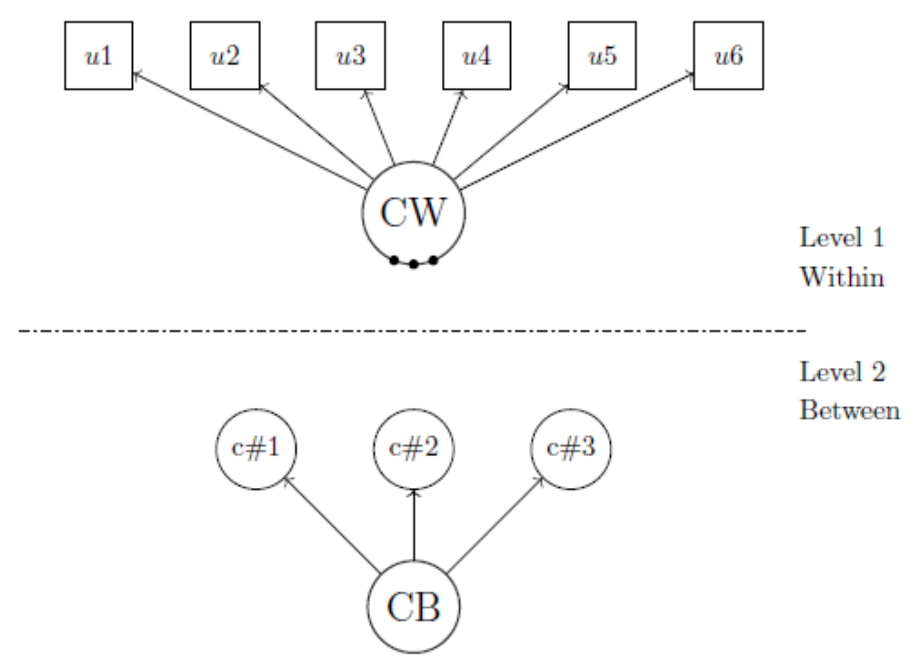

Figure 1. Multilevel latent class model. The diagram is drawn using the conventions used in Henry and Muthén (2010).

\subsection{Analytical approach}

The multilevel latent class analysis proceeded in two phases. First, an individual-level model of respondent types was selected by estimating a series of standard single-level LCA models. To identify the ideal number of latent classes, models of 1 to 6 classes were tested. Second, using the selected individual-level model specification, we applied multilevel LCA to examine the number of latent classes at the country level. LCA and MLCA were conducted with version 7.4 of the Mplus program (Muthén and Muthén, 2012) using robust maximum likelihood (MLR) estimation. ${ }^{6}$

Both substantive and statistical criteria were used to evaluate and select the final model. Fit criteria included model convergence, Akaike information criterion (AIC), Bayesian information criterion (BIC), log-likelihood value, sample sizes per class, and theoretically meaningful interpretability. Comparatively lower BIC and AIC values indicated better model fit to the data. Entropy was used to examine how accurate

${ }^{6}$ A set of Mplus commands for the selected models is included in Appendix B. 
the model predicts latent class membership, with values above 0.80 indicating better separation of the classes (Vermunt and Magidson, 2002).

\subsection{Data and measurement}

To examine the typology of trust orientations, we used data from the Eurobarometer 81.4. Survey fieldwork was conducted in spring 2014. For the purposes of our study, the Eurobarometer survey is an important source of data. More specifically, whereas the Eurobarometer political trust items overlap to a large extent with the items used in the European Social Survey (ESS), the Eurobarometer data contain more items on trust in the European institutions. ${ }^{7}$ In addition, the dichotomous formulation of trust items ('tend to trust' vs. 'tend not to trust') allows for the most suitable input for MLCA. Furthermore, in their study, Armingeon and Ceka (2014) rely on the Eurobarometer data when analyzing the four types of EU support. Using the same data source enables us to examine whether there is any correspondence between their findings and ours. Given that the focus of our study is on EU support, we limit our analysis to the 28 EU member states. The observations that had missing values on all trust variables were deleted. The resulting sample size contains 27,674 respondents. To ensure valid inferences, all the analyses were conducted on weighted data using weights provided by the Eurobarometer. The size of each national sample, the percentage of missing values per country on trust variables, and the corresponding weight can be found in Appendix A, Table 1.

Unlike prior research that has mostly focused on analyzing trust in a single EU institution ${ }^{8}$---often the European Parliament---and unlike the studies of Martinotti and Stefanizzi (1995) and Armingeon and Ceka (2014), in which only two indicators were used for cross-tabulation, in our study six indicators reflecting trust in various institutions were selected for inclusion in the analysis (Table 2). Two of the institutions are located at the national level (national government and national parliament) and four at the

\footnotetext{
${ }^{7}$ At the European level, the ESS contains only the indicator for Trust in the European Parliament.

${ }^{8}$ Two recent exceptions are the studies by Torcal and Christmann (2019) and by Drakos et al. (2019).
} 
European level (European Union, the European Parliament, European Commission, European Central Bank). ${ }^{9}$ The wording of the original question is stated in the following way: "I would like to ask you a question about how much trust you have in certain institutions. For each of the following institutions, please tell me if you tend to trust it or tend not to trust it" (Eurobarometer, 2014).

The cursory look at Table 2 shows that on aggregate, disregarding the country level, respondents tend to trust EU institutions more than their domestic political institutions. The European Parliament enjoys the most trust (43.20\%) while national governments the least (28.69\%). Our empirical analysis will show whether this aggregate approach masks some important nuances.

Table 2. Indicators of trust in political institutions used in the analysis.

\begin{tabular}{llc}
\hline Indicator & & Tend to trust (\%) \\
\hline \multirow{4}{*}{ Trust in } & National Government & 28.69 \\
& National Parliament & 29.99 \\
& European Union & 35.51 \\
& European Parliament & 43.20 \\
& European Commission & 41.35 \\
& European Central Bank & 38.84
\end{tabular}

Source: Eurobarometer 81.4 (2014), N = 24,674. Weighted data.

\section{Empirical results}

\subsection{Single-level latent class analysis}

\footnotetext{
${ }^{9}$ The Eurobarometer 81.4 (2014) contains two additional indicators of trust in institutions at the national level, namely 'Trust in Political Parties' and 'Trust in Regional and Local Public Authorities'. However, we chose not to include these two items in the final analysis. The indicator of Trust in Political Parties did not help in distinguishing between latent classes and the indicator of Trust in Regional Politics represents a subnational institutional level, which is not the focus of the current study.
} 
In the first analytical step, we conducted a standard single-level LCA of six trust indicators without taking into account the clustering of respondents in countries. Models containing one to six latent classes were fitted to the data. Table 3 presents, for each model, the number of latent classes included, the number of free parameters, the BIC, the AIC, the log-likelihood value, and the entropy value.

Although the values of the BIC and the AIC are decreasing up through the six-class model, it is evident that after the four-class model the improvement in fit is only marginal. Given that the five- and sixclass solutions are clearly not preferable because of the small reduction in log-likelihood and lower entropy values, we investigated the results of both the three-class and four-class solutions. The Lo-Mendell-Rubin adjusted likelihood ratio test (LRT) p-values (four-class > three-class, $\mathrm{p}<0.001$ ), indicates that the fourclass model is superior to models with three or fewer classes. Based on the fit statistics, the relatively high entropy value for the four-class model indicating a good separation of the latent classes $(0.823)$, and the interpretability of the classes, we adopted the four-class solution.

Table 3. Single-level Latent Class Analysis (LCA) model fit statistics for trust orientations.

\begin{tabular}{llllll}
\hline Model & $\begin{array}{c}\text { \# Free } \\
\text { parameters }\end{array}$ & $\begin{array}{c}\text { Log- } \\
\text { likelihood }\end{array}$ & BIC & AIC & Entropy \\
\hline One-class LCA & 6 & -93731.150 & 187523.670 & 187474.300 & 1.00 \\
Two-class LCA & 13 & -69697.234 & 139527.435 & 139420.467 & 0.858 \\
Three-class LCA & 20 & -66370.095 & 132944.755 & 132780.190 & 0.857 \\
Four-class LCA & $\mathbf{2 7}$ & $\mathbf{- 6 4 1 8 7 . 9 8 1}$ & $\mathbf{1 2 8 6 5 2 . 1 2 4}$ & $\mathbf{1 2 8 4 2 9 . 9 6 2}$ & $\mathbf{0 . 8 2 9}$ \\
Five-class LCA & 34 & -64085.080 & 128517.921 & 128238.160 & 0.817 \\
Six-class LCA & 41 & -64031.937 & 128483.232 & 128145.873 & 0.786 \\
\hline
\end{tabular}

Note: $\overline{\mathrm{BIC}}=$ Bayesian information criterion. $\mathrm{AIC}=$ Akaike Information Criterion. Bold text indicates the preferred model.

Table 4 presents the information on prevalence of each latent class and the conditional probability estimates for the four-class model. The largest class contains approximately $48 \%(n=13,262)$ of survey respondents. Members of this latent class have a low probability of trusting political institutions both at the national and at the EU level. We label this class the 'Sceptic'. The second largest class identified by LCA is the 
'Trusting' type comprising $21 \%(\mathrm{n}=5,796)$ of the respondents. This group includes respondents with a high probability of trusting both national and EU institutions. The third latent class represents $19 \%(\mathrm{n}=$ $5,315)$ of the sample. The defining characteristic of Class 3 is a low probability of trusting national political institutions and a high probability of trusting EU institutions. Therefore, we label this class, the 'EU Supporter'. The final and the smallest class with only $12 \%(n=3,296)$ of survey respondents is characterized by a high probability of trusting national institutions and a low probability of trusting the European institutions. This class is labeled the 'Nationalist.'

Table 4. The prevalence of cases in each latent class and the predicted probability of trust attitude conditioned on the latent class assignment.

\begin{tabular}{|c|c|c|c|c|c|c|c|c|}
\hline \multirow{2}{*}{$\begin{array}{l}\begin{array}{l}\text { Latent class } \\
\text { prevalence }\end{array} \\
\text { Item response } \\
\text { probabilities }\end{array}$} & \multicolumn{2}{|c|}{$\begin{array}{c}\text { Class 1: Sceptic } \\
48 \%\end{array}$} & \multicolumn{2}{|c|}{$\begin{array}{c}\text { Class 2: Trusting } \\
21 \%\end{array}$} & \multicolumn{2}{|c|}{$\begin{array}{c}\text { Class 3: EU Supporter } \\
19 \%\end{array}$} & \multicolumn{2}{|c|}{$\begin{array}{c}\text { Class 4: Nationalist } \\
12 \%\end{array}$} \\
\hline & Trust & No trust & Trust & No trust & Trust & No trust & Trust & No trust \\
\hline $\begin{array}{l}\text { Trust in National } \\
\text { Government }\end{array}$ & 0.018 & 0.982 & 0.891 & 0.109 & 0.058 & 0.942 & 0.699 & 0.301 \\
\hline $\begin{array}{l}\text { Trust in National } \\
\text { Parliament }\end{array}$ & 0.004 & 0.996 & 0.929 & 0.071 & 0.055 & 0.945 & 0.817 & 0.183 \\
\hline $\begin{array}{l}\text { Trust in the } \\
\text { European Union }\end{array}$ & 0.062 & 0.938 & 0.887 & 0.113 & 0.559 & 0.441 & 0.300 & 0.700 \\
\hline $\begin{array}{l}\text { Trust in European } \\
\text { Parliament }\end{array}$ & 0.033 & 0.967 & 0.979 & 0.021 & 0.923 & 0.077 & 0.269 & 0.731 \\
\hline $\begin{array}{l}\text { Trust in European } \\
\text { Commission }\end{array}$ & 0.018 & 0.982 & 0.979 & 0.021 & 0.951 & 0.049 & 0.178 & 0.818 \\
\hline $\begin{array}{l}\text { Trust in Central } \\
\text { Bank }\end{array}$ & 0.056 & 0.944 & 0.881 & 0.119 & 0.766 & 0.234 & 0.290 & 0.710 \\
\hline
\end{tabular}

Note: The highest probability per class is indicated in boldface. All statistically significant at 0.001 level.

Figure 2 shows the profiles of trust orientations for the four-class model, where the x-axis indicates a set of political institutions and the $y$-axis refers to the average probability of trusting each institution. The four lines represent the trusting patterns for the four latent classes with higher values indicating higher likelihood to be more trusting of the institution, as compared to its average evaluation among the respondents. For 
example, it is clearly visible that the members of the 'Sceptic' class have a very low probability of trusting any of the studied institutions, while the members of the 'Trusting' class have very high probability of trusting each of the institutions analyzed. The fact that the lines for the 'EU Supporter' and the 'Nationalist' class cross each other indicate that these estimated latent classes differ in regard to the type of institution being trusted. If the lines are parallel to each other, as is the case with the 'Sceptic' and the 'Trusting' class, then this indicates that the classes differ in regard to the level or degree of trust (e.g., low trust, moderate trust, and high trust), rather than a particular type of political institution.

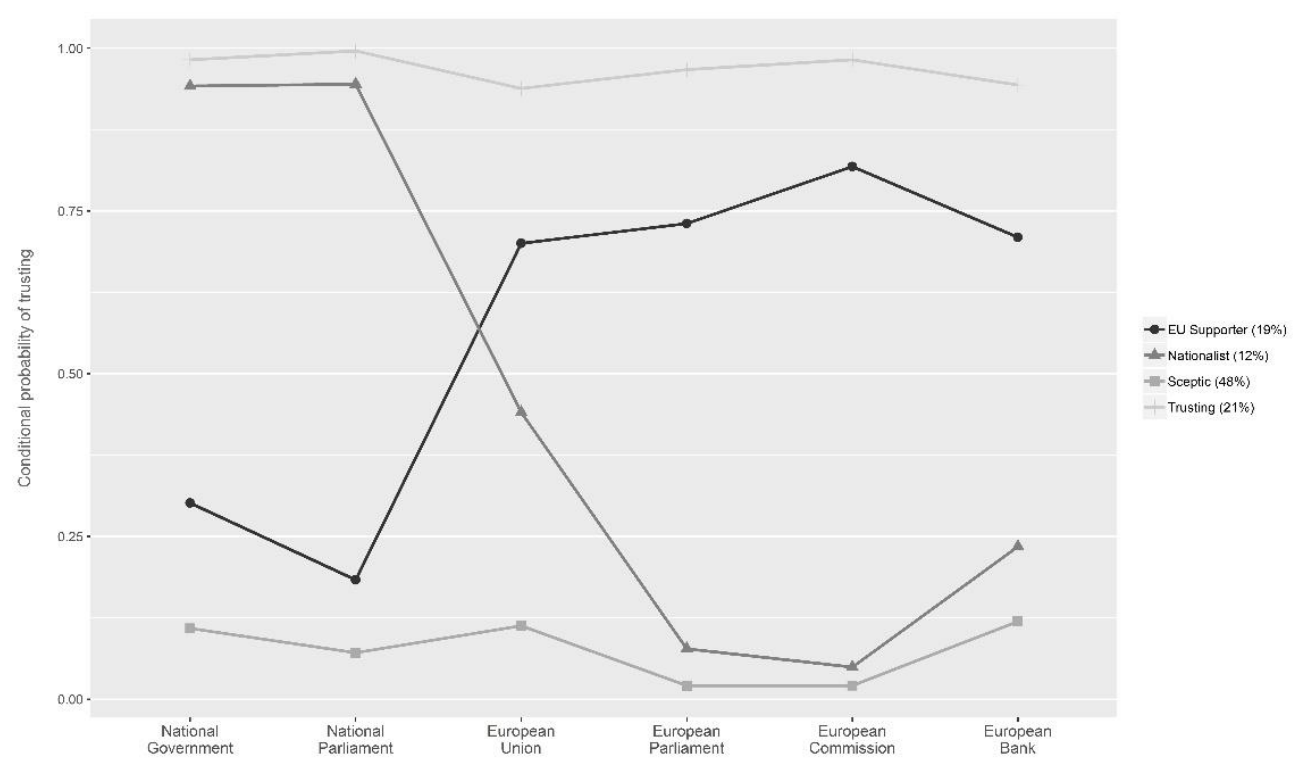

Figure 2. Predicted probabilities of reporting trust for each institutional item, conditioned on Level 1 latent class assignment.

\subsection{Multilevel latent class analysis}

Building on the four-class solution at Level 1, we specified a multilevel model that utilized the nonparametric approach to account for the hierarchical structure of the Eurobarometer data. We estimated models with two, three, and four classes at the country level. The results of the estimation are presented in Table 5. 
The multilevel model with four classes at the country level had encountered several problems with convergence and identification so we did not pursue it further. Considering the limited number of clusters at Level 2 we re-estimated the models with two and three classes to ensure that log-likelihood was replicated. ${ }^{10}$ The BIC, the AIC, and the entropy values of the model with three latent classes at the country level were better compared to the values from the two-class model (Table 5). In addition, the latent classes at Level 2 were better distinguished in the model with three classes, as compared to the model with only two classes. We therefore concluded that the multilevel model with four classes at the level of individuals and three classes at the country level fits the data best. It is also important to note that the entropy value of the multilevel model (0.916) was better than that of the single-level model (0.829) suggesting the existence of contextual effects that can have influence on the individual-level latent class indicators.

Table 5. Multilevel Latent Class Analysis (MLCA) model fit statistics for trust orientations.

\begin{tabular}{llll}
\hline & \multicolumn{3}{c}{ Number of Level 2 classes } \\
\cline { 2 - 4 } Model fit & 2 Class & 3 Class & 4 Class \\
\hline No. of free parameters & 31 & 35 & Non-identified \\
Log-likelihood & -65438.444 & -65006.770 & \\
BIC & 131193.963 & 130371.529 & \\
AIC & 130938.887 & 130260.299 & \\
Entropy & 0.897 & 0.916 & \\
\hline
\end{tabular}

Note: $\mathrm{BIC}=$ Bayesian information criterion. AIC = Akaike Information Criterion.

Table 6 presents the individual latent class probabilities in each of the three latent classes at Level 2. Within the three latent country classes, the individual latent class probabilities differ substantially. As can be seen

\footnotetext{
${ }^{10}$ We re-estimated the final model (with 3 latent classes at the country level) using a set of constrains on model parameters to ensure model identification. The results of the re-estimated model correspond to the results of the model without such constraints, supporting the robustness of our findings.
} 
in Table 6, the probability of the 'Sceptic' class varies most over country classes (between 0.091 and 0.236 ), followed by that of the 'EU Supporter' class (between 0.042 and 0.138), and that of the 'Trusting' class (between 0.046 and 0.105 ). The probability of the 'Nationalist' class varies relatively little over country classes (between 0.015 and 0.072 ). The largest country class is characterized by a high probability of the 'Sceptic' class, the second largest country class by a high probability of 'EU Supporter' class, and the smallest country class by substantial probabilities for 'Trusting' and 'Sceptic' classes. Accordingly, we label these three country-level latent classes, the 'Sceptic', the 'EU Supporter' and the 'Divided' class.

Table 6. Random effects nonparametric MLCA model classification.

\begin{tabular}{lllll}
\hline & \multicolumn{4}{l}{ Latent individual class probability } \\
Latent country class probability & Class 1: & Class 2: & Class 3: & Class 4: \\
& Trusting & Nationalist & Sceptic & EU Supporter \\
\hline Class 1: 'Sceptical' $(\mathrm{P}=0.40)$ & 0.086 & 0.028 & $\mathbf{0 . 2 3 6}$ & 0.049 \\
Class 2: 'Ambivalent' $(\mathrm{P}=0.26)$ & $\mathbf{0 . 1 0 5}$ & 0.015 & $\mathbf{0 . 0 9 4}$ & 0.042 \\
Class 3: 'EU Supporter' $(\mathrm{P}=0.34)$ & 0.046 & 0.072 & 0.091 & $\mathbf{0 . 1 3 8}$ \\
\hline
\end{tabular}

Figure 3 shows how the four individual-level latent classes are distributed among the three country-level classes. The 'Sceptic' latent class represents $40 \%$ of the respondents. This class is comprised of countries with a relatively large number of respondents with a low level of trust in any of the studied institutions (i.e. $59.1 \%$ of the respondents). The 'EU Supporter' class is comprised of countries with a large share of EU supporters (39.8\%). This group of European countries represents $34 \%$ of the respondents. Finally, the 'Divided' group of countries, representing about $26 \%$ of the respondents, has an almost equal share of respondents who belong to 'Trusting' $(41.2 \%)$ and to 'Sceptic' (36.7\%) class. Interestingly, our analysis does not identify a 'Nationalist' cluster at the country level. It is also important to note that the size of the 'Sceptic' class is relatively large in all three country clusters. 


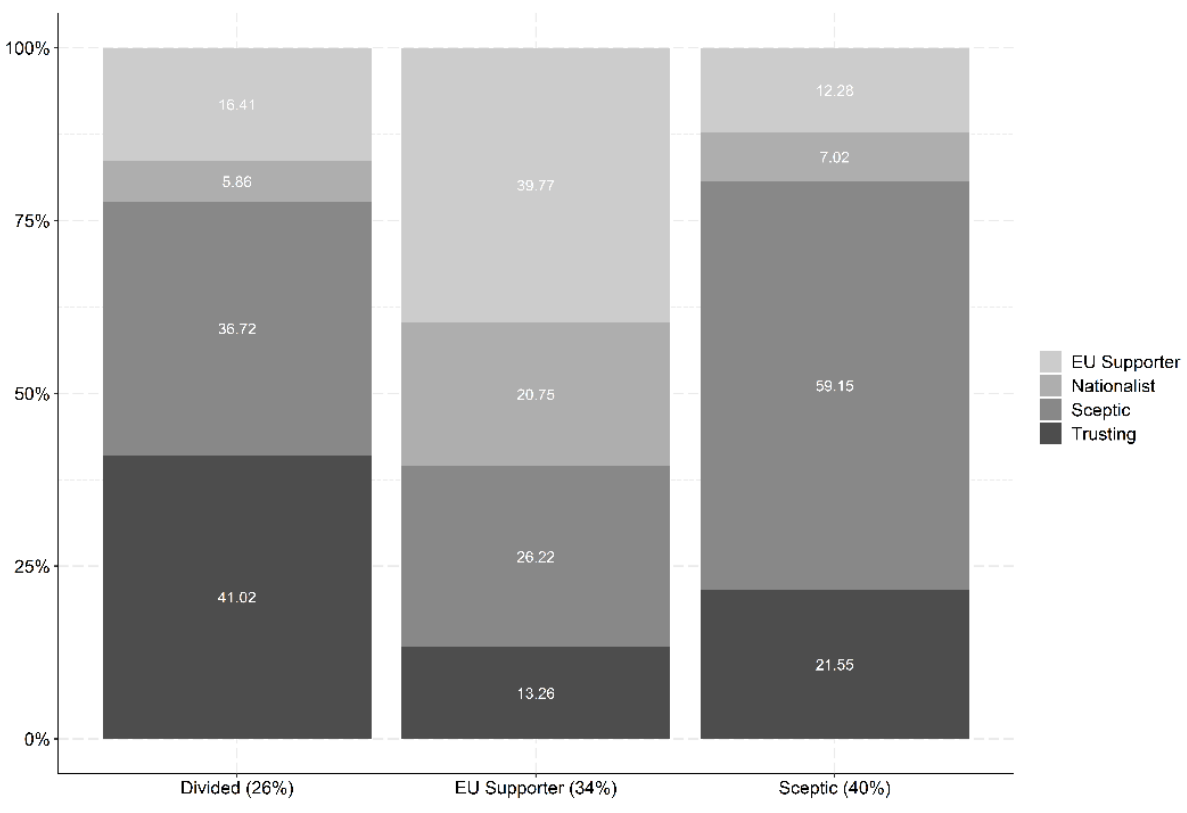

Figure 3. Distribution of individual-level latent classes within country-level latent classes.

In addition to identifying country-level latent classes, multilevel latent class analysis allows for the classification of countries into the identified latent groups. Using the conditional probabilities generated by multilevel LCA, the countries in the sample have been assigned to one of the three latent types. In total, 10 countries were assigned to the 'EU Supporter' cluster, 11 countries to the 'Sceptic' and 7 countries to the 'Divided' class. On the basis of this classification, we can clearly discern three geographical segments, as presented in Figure 4. 


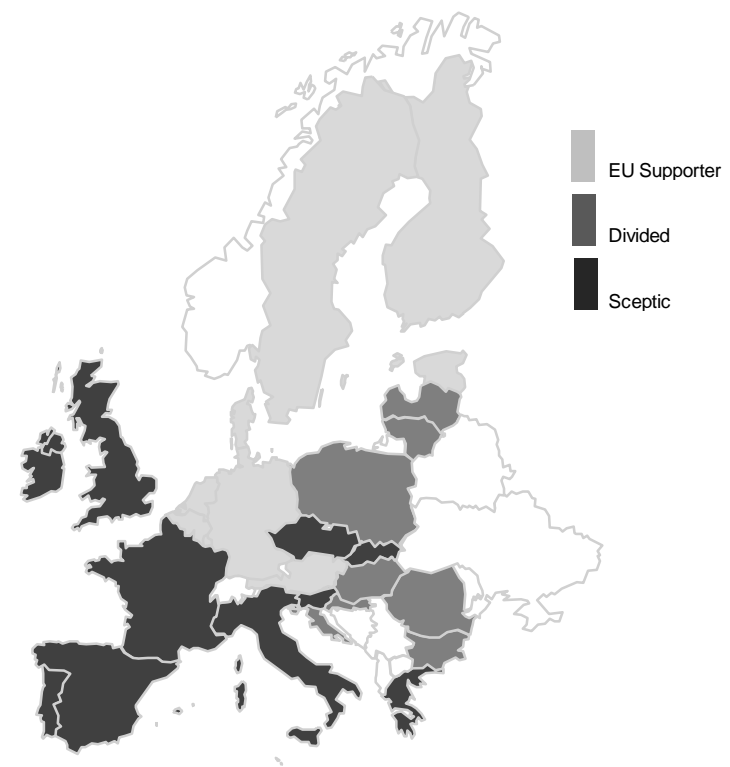

Figure 4. Country classes posterior membership.

The Northern European countries (Sweden, Finland and Denmark) and also one of the Baltic countries (Estonia) belong to the 'EU Supporter' class and are characterized by the largest percentage of EU supporters. The Benelux countries along with Austria and Germany also belong to this cluster. By contrast, Mediterranean countries are characterized by a large number of respondents with a low probability of trusting any of the analyzed institutions. These countries belong to the 'Sceptic' group at the country level. France, the United Kingdom, and Ireland also belong to this cluster along with three East European countries (The Czech Republic, Slovenia and Slovakia). The remaining East European countries belong to the 'Divided' class and are comprised of individuals with similar probabilities for sceptical and trusting attitudes. The more detailed information on the country assignment is presented in Appendix A, Table 2.

\section{Discussion and conclusion}

The main aim of this article was to demonstrate the utility of the person-centered perspective as a complement to the variable-oriented approach adopted by most prior research on public attitudes towards 
the EU. While few would deny the importance of holistic approach to analyzing different attitudinal profiles, the use of the person-oriented approach continues to be uncommon. In this study, we introduce and explain the main tenets of the person-centered approach and illustrate its application to the current debate on the relationship between trust in institutions at the national and EU level. In so doing, we respond to the call for a more "conceptual and empirical refinement" of EU attitudes, in general, and of such concepts as EU support and Euroscepticism, in particular (Boomgaarden et al., 2011, p. 241; see also Krouwel and Abts, 2007).

As noted in the introduction, this article makes conceptual, empirical, and methodological contributions to the literature on trust in political institutions at national and EU level. Conceptually, by introducing the person-orientated approach we shift the analytical focus from the variable to the individual. This conceptual change of emphasis allows us to examine the configuration of trust attitudes within individuals rather than trust attitudes in and by themselves. As a consequence, we recast the current debate about the relationship between trust attitudes towards national and EU institutions, in terms of multidimensionality, rather than predictor-outcome linkages. Thus, the suggested approach represents a promising alternative to a conventional variable-oriented perspective that appears to have reached an impasse when it comes to analyzing the relationship between trust in national and EU institutions.

To this end, empirically, the present study is the first to investigate and to validate the existence of distinct groups of citizens representing contrasting profiles of trust orientations towards national and European institutions. The discovered typology underscores the fact that one can distinguish different combinations of trust attitudes across Europe, a conclusion also supported in a recent study of Wu and Wilkes (2018). This result directly challenges the assumption of homogeneity of population adopted in the variable-oriented studies and underlines the importance of exploring heterogeneity (see also Baldassarri and Goldberg, 2014). On a practical level, by underscoring heterogeneity of trust profiles, our findings caution the policymakers against adopting a 'one-size-fits-all' solution when addressing the decline in institutional trust. Furthermore, methodologically, this article provides an illustration of how to use personcentered methodology to construct a rigorous quantitative typology through the application of a single-level 
and multilevel latent class analysis. In fact, the present study constitutes the first application of MLCA to the data on public attitudes towards domestic and EU institutions. By introducing multilevel latent class analysis and illustrating how this method can be applied in practice, we demonstrate the relevance, utility and the potential of MLCA for comparative research.

By adopting the person-oriented perspective, the current study yields important substantive results. First, our individual-level findings provide strong evidence in support of Armingeon and Ceka's (2014) typology of trust orientations towards national and European government. Specifically, based on the analysis of six institutional trust indicators, the results of the LCA analysis confirm the existence of four discrete groups of respondents in a cross-national sample of $28 \mathrm{EU}$ countries. Each of these identified types exhibits a unique profile with a different constellation of trust attitudes. 'Sceptical' citizens tend to be suspicious of all the examined institutions regardless of whether these are located at the national or at the EU level. By contrast, the respondents classified as 'Trusting' exhibit high confidence in all the institutions under study. These two classes differ from each other in the matter of degree of institutional trust (low vs. high). The other two groups can be distinguished not according to the degree of trust but according to the type of trusted political institution. Thus, the 'EU Supporters' score very high on trust in the European institutions and very low on trust in the domestic institutions, while for the 'Nationalists' the opposite is true.

It is, nevertheless, important to note that when labeling the latent classes, we depart somewhat from the terminology of Armingeon and Ceka (2014), who relied on the classification of Martinotti and Stefanizzi (1995). While the 'Trusting' and the 'Nationalist' types were labeled in accordance to Armingeon and Ceka's (2014) terminology, we found that the other two labels, namely, the 'detached' and the 'escapist', do not fully reflect the meaning of these two latent classes. Instead, we used the 'EU Supporter' label to refer to the latent type characterized by a high probability of trust in EU institutions and the 'Sceptic' label to refer to the latent class that has a high probability of low trust in all of the institutions under study. In our opinion, trusting EU institutions while being critical towards domestic institutions does not always mean that one intends to 'escape' the current political system. Similarly, having low trust in institutions 
does not necessarily indicate that an individual is 'detached' or 'alienated' from the political system. Indeed, a number of political trust scholars argue that the lack of public trust may encourage participation and that distrust is important for strengthening democratic institutions (e.g. Lenard, 2008; Mishler and Rose, 1997).

Next, it may be informative to compare the relative ordering and the sizes of the identified groups to those reported in the paper of Armingeon and Ceka (2014). Although not directly comparable given the differences in the methodological approach and in the analyzed time periods, the relative ordering of the latent types is in agreement with the earlier study. The largest class comprises those individuals who exhibit sceptical attitudes towards all the institutions, followed by the 'Trusting' class, then by the 'EU Supporter' class, and, finally, by the 'Nationalist' class. In other words, our findings confirm the conclusion of Armingeon and Ceka (2014) that "[m]ost Europeans either trust both their national government and the EU or neither of them" (p. 99). Nevertheless, the actual size of the established groups between our study and theirs appears to differ. Specifically, if we compare the results of Armingeon and Ceka based on the Eurobarometer data for 2011 with our results based on a sample from 2014, the size of the 'detached' class identified by Armingeon and Ceka is nine percentage points lower than the size of the 'Sceptic' class from our study (39\% and 48\%, respectively). Furthermore, the difference in size between the 'Trusting' class and the 'EU Supporter' (or 'escapist') class is found to be much smaller in our study, compared with the findings of Armingeon and Ceka (two and six percentage points, respectively). Although these differences may be artifacts of the underlying sample or methodology, they may also reflect the actual changes in the distribution of different types. We surmise that the rise in the number of respondents with sceptical and nationalist views may be a consequence of the economic and financial crisis of 2008-2010.

In the conclusion to their exploratory study, Martinotti and Stefanizzi (1995) write that "What is most striking, however, is the diversity of orientations revealed by applying this typology at the national level" (p. 188). Our results, utilizing a more rigorous methodology, provides evidence to substantiate this statement. Specifically, through the application of the multilevel latent class analysis we identified three latent classes at the country level. Each of the country-level types, 'Sceptic', 'EU Supporter', and 'Divided', is characterized by a different distribution of Level 1 latent classes. These results provide evidence of a 
substantial heterogeneity of trusting profiles not only within but also across European countries. Furthermore, the fact that the latent country groups were found to have considerable differences in individual latent class probabilities highlights the importance of analyzing contextual effects. Using a single-level approach masks the impact of country-level influences and potentially omits a crucial part of the explanation for the latent types and their relative sizes and distribution. The fact that in our sample of data for 2014, Southern European countries (Italy, Spain, Portugal, Greece) together with Ireland were found to belong to the 'Sceptic' cluster is consistent with the interpretation that the economic crisis of 20082010 had lasting negative effects on trust attitudes in these countries. We can conjecture based on previous work, but it remains for future research to explore, that the decline in macroeconomic conditions, poor national performance, and/or EU policies of austerity and fiscal consolidation are responsible for a larger share of sceptics in these nations (Ares et al., 2017; Armingeon and Ceka, 2014; Drakos et al., 2019; Gomez, 2015, Torcal and Christmann, 2019).

Interestingly, though perhaps not surprisingly, considering that the study of Martinotti and Stefanizzi (1995) relied on a different set of indicators, limited number of countries, and used the Eurobarometer data from 1975 to 1993, our findings at the country-level diverge. Specifically, we identified only three country-level classes, as compared to four established in their study. Further, in contrast to their typology, our analysis did not reveal a predominately 'integrated' ('Trusting') type of orientation at the country level. Instead, the 'Sceptic' group was very clearly identified. Similarly, the 'Divided' type, distinguished in our study, was not included in their typology. Consequently, the composition of countries that belong to each specific type of orientation also differs. To provide an example, while in Martinotti and Stefanizzi's typology Denmark and Germany belong to the 'integrated plus nation statist' type, in ours these two countries were assigned to the 'EU supporter' type. Nevertheless, considering the gap of almost three decades between the two studies and significant changes in the economic, social and political landscape, these results warrant further (retrospective) investigation rather than falsify earlier findings.

Finally, compared to the results of the variable-centered studies, our country-level analysis reveals a different classification of countries based on the distribution of trust profiles. For example, by relying on 
correlation between two indicators from the Eurobarometer survey, namely trust in national parliament and trust in the EU, Muñoz (2017) shows that, on average, in Sweden, Finland, Denmark, and the Netherlands citizens tend to trust their national parliaments more than they trust the EU. These results would classify these countries as more nationalist. However, given that the analyses in Muñoz (2017) were conducted at the national level using mean comparisons, they cannot reveal the diversity of trust dispositions within each specific country. By contrast, our findings indicate that although a segment of population in these countries holds nationalist views, the majority of citizens belong to the 'EU Supporter' class and that a significant share of the population belongs to the 'Sceptic' class. These types of insights into a heterogeneous structure of European population and the actual distribution of trust orientations within EU countries would not be possible by using solely the variable-oriented perspective.

It is important to remark on certain limitations of this study, which, in turn, suggest exciting avenues for future research. First, given the scope of the present article, we did not examine whether the identified latent types are also distinctive in terms of the background characteristics of group members. In our view, such an analysis constitutes a logical extension of this work. It may, for example, very well be that the sociodemographic and other individual-level characteristics of the 'Nationalists' and the 'Sceptics' are different from the 'EU Supporters' or the 'Trusting' type. For instance, prior research has demonstrated that such factors as the level of education, political ideology, and knowledge of EU politics can serve as salient predictors of attitudes towards EU (Gabel and Palmer, 1995; Martinotti and Stefanizzi, 1995). Furthermore, given the importance of context for explaining EU support (Ares et al., 2017; Torcal and Christmann, 2019), future studies should investigate the determinants of the identified latent types by including contextual predictors. In this line of research, it will be fruitful to investigate the claim of Martinotti and Stefanizzi (1995) that "historical and contextual variables have the most effect in shaping the various combinations of attitudes towards governance at the national and international levels" (p. 189). National economic performance, for example, may be found to account for the greater share of sceptical respondents in the Mediterranean countries. The indicator for corruption at the national level can provide 
another valuable contextual predictor (Della Porta, 2000; Uslaner, 2008; Harteveld et al., 2013). ${ }^{11}$ To this end, multilevel latent class analysis could be of great benefit as MLCA constitutes a flexible yet powerful approach that can incorporate predictors both at the individual and at the country level.

Moreover, considering the scope of the present study, we did not have an opportunity to relate the individual-level typology to other important social attitudes or policy preferences recognized in the literature on EU support. For example, building on the recent work in this area, it might be fruitful to analyze the differences between the four classes in their outlook on EU integration and EU economic governance, while controlling for relevant sociodemographic and socioeconomic characteristics. Such an investigation, apart from generating new substantive insights, may provide a valuable example of how the variablecentered and the person-centered approaches can be integrated to provide a richer understanding of public attitudes.

It is also important to acknowledge that the results of MLCA may be sensitive to the current sample as well as to the political institutions considered. Interestingly but perhaps unsettling for the future of the European democracies, our findings indicate that the 'Sceptical' respondents constitute the largest group in the sample of the Eurobarometer data from 2014. At the same time, the 'Nationalist' type is shown to be the smallest compared to the other three groups. Whether the ordering and the proportions of latent classes will remain the same is an interesting empirical question for future studies, especially considering the rise of nationalist and Eurosceptic attitudes in recent years. Furthermore, performing a similar analysis using survey data from previous years in order to compare the structure and the distribution of latent classes over time could prove equally insightful. Altogether, the development of trajectories of trust orientations across EU countries provides an exciting avenue for future research.

\footnotetext{
${ }^{11}$ Given the results of Martinotti and Stefanizzi (1995), who demonstrated that the association of individuallevel variables, such as left-right ideology and awareness of the European Community, with a specific type of orientation varies across countries, it may also be informative to examine the influence of the interaction effects.
} 
In conclusion, while the variable-oriented approach has been central to the study of EU attitudes, it provides only one set of lenses through which the relationship between trust attitudes towards institutions at different levels of governance can be analyzed. We believe that an application of the person-centered approach has the potential to contribute to the development of a more comprehensive theoretical understanding of institutional trust and public support for the EU. We hope that the present study serves as a first step in promoting application of a person-centered framework in this area. 


\section{References}

Anderson, C. J. (1998). When in doubt, use proxies: Attitudes toward domestic politics and support for European integration. Comparative Political Studies, 31(5), 569-601.

Ares, M., Ceka, B. \& Kriesi, H. (2017). Diffuse support for the European Union: Spillover effects of the politicization of the European integration process at the domestic level. Journal of European Public Policy, 24(8), 1091-1115.

Armingeon, K. \& Ceka, B. (2014). The loss of trust in the European Union during the Great Recession since 2007: The role of heuristics from the national political system. European Union Politics, 15(1), 82107.

Armingeon, K. \& Guthmann, K. (2014). Democracy in crisis? The declining support for national democracy in European countries, 2007-2011. European Journal of Political Research, 53(3), 423-442.

Asparouhov, T. \& Muthén, B. O. (2008). Multilevel mixture models. In G. R. Hancock \& K. M. Samuelsen (Eds.), Advances in latent variable mixture models (pp. 27-51). Charlotte, NC: Information Age.

Baldassarri, D. \& Goldberg, A. (2014). Neither ideologues nor agnostics: Alternative voters' belief system in an age of partisan politics. American Journal of Sociology, 120(1), 45-95.

Bergman, L. R. \& Lundh, L.-G. (2015). The person-oriented approach: Roots and roads to the future. Journal for Person-Oriented Research, 1(1-2), 1-6.

Bergman, L. R., Magnusson, D. \& El Khouri, B. M. (2003). Studying individual development in an interindividual context: A person-oriented approach. Psychology Press. 
Bonikowski, B. (2017). Nationhood as cultural repertoire: Collective identities and political attitudes in France and Germany. In M. Skey \& M. Antonsich (Eds.), Everyday nationhood: Theorising culture, identity and belonging after banal nationalism (pp. 147-174). Springer.

Bonikowski, B. \& DiMaggio, P. (2016). Varieties of American popular nationalism. American Sociological Review, 81(5), 949-980.

Boomgaarden, H. G., Schuck, A. R., Elenbaas, M. \& De Vreese, C. H. (2011). Mapping EU attitudes: Conceptual and empirical dimensions of Euroscepticism and EU support. European Union Politics, 12(2), $241-266$.

De Vries, C. E. (2018). Euroscepticism and the future of European integration. Oxford University Press.

Della Porta, D. (2000). Social capital, beliefs in government, and political corruption. In S. J. Pharr \& R. D. Putnam (Eds.), Disaffected democracies: What's troubling the trilateral countries (Chap. 10, pp. 202228). Princeton, NJ: Princeton University Press.

Drakos, K., Kallandranis, C. \& Karidis, S. (2019). Determinants of trust in institutions in times of crisis: Survey-based evidence from the European Union. JCMS: Journal of Common Market Studies.

Easton, D. (1965). A systems analysis of political life. New York: John Wiley \& Sons.

Easton, D. (1975). A re-assessment of the concept of political support. British Journal of Political Science, 5(4), 435-457.

Finch, W. H. \& French, B. F. (2014). Multilevel latent class analysis: Parametric and nonparametric models. The Journal of Experimental Education, 82(3), 307-333.

Fisher, J., Van Heerde, J. \& Tucker, A. (2010). Does one trust judgement fit all? Linking theory and empirics. The British Journal of Politics and International Relations, 12(2), 161-188. 
Gabel, M. \& Palmer, H. D. (1995). Understanding variation in public support for European integration. European Journal of Political Research, 27(1), 3-19.

Goldberg, A. (2011). Mapping shared understandings using relational class analysis: The case of the cultural omnivore reexamined. American Journal of Sociology, 116(5), 1397-1436.

Gomez, R. (2015). The economy strikes back: Support for the EU during the Great Recession. JCMS: Journal of Common Market Studies, 53(3), 577-592.

Goodman, L. A. (1974). Exploratory latent structure analysis using both identifiable and unidentifiable models. Biometrika, 61(2), 215-231.

Hagenaars, J. A. (1993). Loglinear models with latent variables. Sage. Harteveld, E., Van der Meer, T. \& Vries, C. E. (2013). In Europe we trust? Exploring three logics of trust in the European Union. European Union Politics, 14(4), 542-565.

Henry, K. L. \& Muthén, B. (2010). Multilevel latent class analysis: An application of adolescent smoking typologies with individual and contextual predictors. Structural Equation Modeling, 17(2), 193-215.

Hooghe, M. (2011). Why there is basically only one form of political trust. The British Journal of Politics and International Relations, 13(2), 269-275.

Hooghe, M. \& Oser, J. (2015). The rise of engaged citizenship: The evolution of citizenship norms among adolescents in 21 countries between 1999 and 2009. International Journal of Comparative Sociology, 56(1), 29-52.

Hooghe, M., Oser, J. \& Marien, S. (2016). A comparative analysis of 'good citizenship': A latent class analysis of adolescents' citizenship norms in 38 countries. International Political Science Review, 37(1), $115-129$. 
Hooghe, M. \& Zmerli, S. (2011). Introduction: The context of political trust. In S. Zmerli \& M. Hooghe (Eds.), Political trust: Why context matters (Chap. 1, pp. 1-11). ECPR Press.

Huang, C. (2005). Dimensions of Taiwanese/Chinese identity and national identity in Taiwan: A latent class analysis. Journal of Asian and African Studies, 40(1-2), 51-70.

Kritzinger, S. (2003). The influence of the nation-state on individual support for the European Union. European Union Politics, 4(2), 219-241.

Krouwel, A. \& Abts, K. (2007). Varieties of Euroscepticism and populist mobilization: Transforming attitudes from mild Euroscepticism to harsh Eurocynicism. Acta Politica, 42(2-3), 252-270.

Kumlin, S. (2011). Claiming blame and giving credit? Unintended effects of how government and opposition frame the Europeanization of welfare. European Union Politics, 12(4), 575-595.

Lazarsfeld, P. F. \& Henry, N. W. (1968). Latent structure analysis. Houghton Mifflin Co.

Lenard, P. T. (2008). Trust your compatriots, but count your change: The roles of trust, mistrust and distrust in democracy. Political Studies, 56(2), 312-332. Magnusson, D. (1983). Implications and applications of an interactional perspective for human development. In D. Magnusson \& V. Allen (Eds.), Human development: An interactional perspective (pp. 369-387). New York: Academic Press.

Mair, P. (2013). Ruling the void: The hollowing of Western democracy. Verso Trade.

Martinotti, G. \& Stefanizzi, S. (1995). Europeans and the nation state. In N. O \& S. R (Eds.), Public opinion and internationalized governance (pp. 163-189). Oxford: Oxford University Press.

McCutcheon, A. L. (1987). Latent class analysis. Sage. 
Mishler, W. \& Rose, R. (1997). Trust, distrust and skepticism: Popular evaluations of civil and political institutions in post-communist societies. The Journal of Politics, 59(2), 418-451.

Morselli, D. \& Glaeser, S. (2018). Economic conditions and social trust climates in Europe over ten years: An ecological analysis of change. Journal of Trust Research, 8(1), 68-86.

Morselli, D. \& Passini, S. (2012). Disobedience and support for democracy: Evidences from the World Values Survey. The Social Science Journal, 49 (3), 284- 294.

Muñoz, J. (2017). Political trust and multilevel government. In S. Zmerli \& T. Van der Meer (Eds.), Handbook on political trust (Chap. 5, pp. 69-88). Cheltenham: Edward Elgar Publishing.

Muñoz, J., Torcal, M. \& Bonet, E. (2011). Institutional trust and multilevel government in the European Union: Congruence or compensation? European Union Politics, 12(4), 551-574.

Muthén, B. O. \& Muthén, L. K. (2012). Mplus 7 base program. Los Angeles, CA: Muthén \& Muthén.

Oser, J., Hooghe, M. \& Marien, S. (2013). Is online participation distinct from offline participation? A latent class analysis of participation types and their stratification. Political Research Quarterly, 66(1), 91101.

Rohrschneider, R. (2002). The democracy deficit and mass support for an EU-wide government. American Journal of Political Science, 463-475.

Rohrschneider, R. \& Loveless, M. (2010). Macro salience: How economic and political contexts mediate popular evaluations of the democracy deficit in the European Union. The Journal of Politics, 72(4), 10291045 .

Sánchez-Cuenca, I. (2000). The political basis of support for European integration. European Union Politics, 1(2), 147-171. 
Torcal, M. \& Christmann, P. (2019). Congruence, national context and trust in European institutions. Journal of European Public Policy, 26(12), 1779- 1798.

Torcal, M., Muñoz, J., Bonet, E., Sanders, D., Pedro, M. \& Toka, G. (2012). Trust in the European Parliament: From affective heuristics to rational cueing. Citizens and the European Polity: Mass Attitudes Towards the European and National Polities, 140.

Uslaner, E. M. (2008). Corruption, inequality, and the rule of law: The bulging pocket makes the easy life. Cambridge University Press.

Van der Meer, T. \& Ouattara, E. (2019). Putting in political trust: An IRT test of the unidimensionality and cross-national equivalence of political trust measures. Quality \& Quantity, 53(6), 2983-3002.

Verhaegen, S., Hooghe, M. \& Quintelier, E. (2017). The effect of political trust and trust in European citizens on European identity. European Political Science Review, 9(2), 161-181.

Vermunt, J. K. (2003). Multilevel latent class models. Sociological Methodology, 33(1), 213-239.

Vermunt, J. K. (2008). Latent class and finite mixture models for multilevel data sets. Statistical Methods in Medical Research, 17(1), 33-51.

Vermunt, J. K. \& Magidson, J. (2002). Latent class cluster analysis. In H. J \& M. A (Eds.), Applied latent class analysis (Chap. 11, pp. 89-106). Cambridge: Cambridge University Press.

Wu, C. \& Wilkes, R. (2018). Finding critical trusters: A response pattern model of political trust. International Journal of Comparative Sociology, 59(2), 110- 138.

Zmerli, S. \& Van der Meer, T. (2017). Handbook on political trust. Cheltenham: Edward Elgar Publishing. 